\title{
Considering built environment and spatial correlation in modelling pedestrian injury severity
}

Prato, Carlo G.; Kaplan, Sigal; Patrier, Alexandre; Rasmussen, Thomas Kjær

Published in:

Traffic Injury Prevention

Link to article, DOI:

10.1080/15389588.2017.1329535

Publication date:

2018

Document Version

Peer reviewed version

Link back to DTU Orbit

Citation (APA):

Prato, C. G., Kaplan, S., Patrier, A., \& Rasmussen, T. K. (2018). Considering built environment and spatial correlation in modelling pedestrian injury severity. Traffic Injury Prevention, 19(1), 88-93.

https://doi.org/10.1080/15389588.2017.1329535

\section{General rights}

Copyright and moral rights for the publications made accessible in the public portal are retained by the authors and/or other copyright owners and it is a condition of accessing publications that users recognise and abide by the legal requirements associated with these rights.

- Users may download and print one copy of any publication from the public portal for the purpose of private study or research.

- You may not further distribute the material or use it for any profit-making activity or commercial gain

- You may freely distribute the URL identifying the publication in the public portal 


\title{
ACCEPTED MANUSCRIPT
}

Considering built environment and spatial correlation in modelling pedestrian injury severity

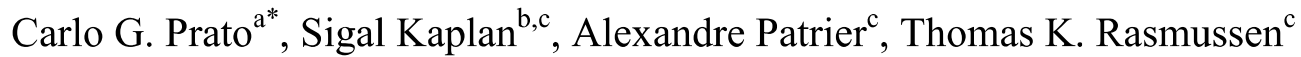
${ }^{\mathrm{a}}$ School of Civil Engineering, The University of Queensland, St. Lucia 4072, Brisbane, Australia

${ }^{\mathrm{b}}$ Department of Geography, Hebrew University of Jerusalem, Mount Scopus, 91905 Jerusalem, Israel

${ }^{\mathrm{c}}$ Department of Management Engineering, Technical University of Denmark, Bygningstorvet 116B, 2800 Kgs. Lyngby, Denmark * corresponding author School of Civil Engineering, The University of Queensland, St. Lucia 4072, Brisbane, Australia, ,E-mail: c.prato@uq.edu.au

\begin{abstract}
Objective. This study looks at mitigating and aggravating factors that are associated with the injury severity of pedestrians when they have crashes with another road user and overcomes existing limitations in the literature by posing attention on the built environment and considering spatial correlation across crashes.
\end{abstract}

Method. Reports for 6539 pedestrian crashes occurred in Denmark between 2006 and 2015 were merged with geographic information system resources containing detailed information about built environment and exposure at the crash locations. A linearised spatial logit model estimated the probability of pedestrians to sustain a severe or fatal injury conditional on the occurrence of a crash with another road user.

Results. This study confirms previous findings about older pedestrians and intoxicated pedestrians being the most vulnerable road users, and crashes with heavy vehicles and in roads 


\section{ACCEPTED MANUSCRIPT}

with higher speed limits being related to the most severe outcomes. This study provides also novel perspectives by showing positive spatial correlation of crashes with the same severity outcome and emphasising the role of the built environment in the proximity of the crash.

Conclusions. This study emphasises the need for thinking about traffic calming measures, illumination solutions, road maintenance programs and speed limit reductions. Moreover, this study emphasises the role of the built environment, as shopping areas, residential areas, and walking traffic density are positively related to a reduction in pedestrian injury severity. Often, these areas have in common a larger pedestrian mass that is more likely to make other road users more aware and attentive, while the same does not seem to apply to areas with lower pedestrian density.

\section{Keywords}

Pedestrian Crashes; Injury Severity Models; Built Environment; Spatial Correlation. 


\section{ACCEPTED MANUSCRIPT}

\section{INTRODUCTION}

Active travel contributes to the sustainability of cities and regions and the health of their inhabitants. Unfortunately, active travellers are the most vulnerable road users when considering that the risk of injury for pedestrians and cyclists is respectively 4.0 and 7.5 times higher than for car occupants (Elvik, 2009).

Having previously looked at the factors associated with cyclist injury severity (Kaplan et al., 2014), this study poses the same research question while turning the attention towards pedestrians. The motivation is fourfold: (i) the development of effective safety policies requires the understanding of not only crash occurrence but also factors affecting injury severity once a crash occurs (Savolainen et al., 2011); (ii) focusing on Denmark allows the use of a crash database integrated with geographic information system (GIS) resources to provide a broad picture of the factors affecting pedestrian injury severity; (iii) focusing on Denmark as an active travel nation serves as an outer marker for highlighting issues and proposing countermeasures (Pucher and Buehler, 2008); (iv) pedestrian safety in Denmark is a top priority when considering that pedestrians account for $15 \%$ of road fatalities and $11 \%$ of serious injuries, but only $2 \%$ of the traffic-km.

Existing literature on pedestrian injury severity investigates generally five types of factors. From the pedestrian perspective, higher injury severity is clearly related to the frailty of older age (Eluru et al., 2008; Clifton et al., 2009; O'Hern et al., 2015; Sasidharan and Menendez, 2015) and the level of intoxication (Eluru et al., 2008; Clifton et al., 2009), while contradicting evidence exists about its relation to gender (Lee and Abdel-Aty, 2005; Abay, 2013; Verzosa and Miles, 2016). From the driver and vehicle perspective, higher injury severity is associated with 


\section{ACCEPTED MANUSCRIPT}

intoxicated drivers (Eluru et al., 2008; Abay, 2013), heavy vehicles (Roudsari et al., 2005; Abay, 2013; Mohamed et at., 2013; Sasidharan and Menendez, 2015), and vehicles with low New Car Assessment Program (NCAP) values (Strandroth et al., 2011). From the behaviour perspective, higher injury severity is linked to pedestrians crossing far from crosswalks (Rothman et al., 2012; Abay, 2013; Sasidharan and Menendez, 2015) or walking along curve road sections (Kim et al., 2008), and drivers going straight and the impact being frontal (Eluru et al., 2008; Abay, 2013; Mohamed et al., 2013). From the roadway perspective, lower injury severity is associated with the presence of medians, sidewalks, crossing buffers, and lower speed limits (Eluru et al., 2008; Abay, 2013; Mohamed et al., 2013; Sasidharan and Menendez, 2015). From an environment perspective, higher injury severity is related to both inclement (Mohamed et al., 2013; Sasidharan and Menendez, 2015) and good weather (Lee and Abdel-Aty, 2005; Eluru et al., 2008), and to both peak (Kim et al., 2008) and night hours (Mohamed et al., 2013; Verzosa and Miles, 2016).

Limitations are identifiable in the existing literature: (i) lack of an overarching analysis considering an extended set of mitigating and aggravating factors; (ii) limited to no attention to the built environment and traffic exposure, with contradicting conclusions concerning both lower (Clifton et al., 2009) and higher (Zahabi et al., 2011) injury severity being associated with transit access, and more severe consequences being related to both urban environments with commercial and parking spaces (Miranda-Moreno et al., 2011; Mohamed et al., 2013) and mixed land uses and proximity to rural areas (Zahabi et al., 2011; Abay, 2013); (iii) ignorance of spatial correlation between crashes although the issue is recognised as essential for modelling injury severity (Castro et al., 2013; Mannering and Bhat, 2014). 


\section{ACCEPTED MANUSCRIPT}

This study addresses these limitations by presenting an extended analysis of mitigating and aggravating factors of pedestrian injury severity for 6539 pedestrian crashes occurred in Denmark between 2006 and 2015. The crashes from the nationwide database were geocoded and matched to GIS resources containing information about built environment and exposure at their locations, and a linearized spatial logit model estimated the probability of the pedestrians sustaining a severe or fatal injury conditional on the crash occurrence while accounting for spatial correlation.

\section{DATA}

\section{Crash Data}

Crash data were extracted from the national database compiled by the Danish Road Directorate on the basis of police reports. Three files compose the database: (i) the crash file lists information about geographical coordinates, collision types, road user maneuvers, involved road users, infrastructure characteristics, and environmental conditions; (ii) the person file lists information about demographics, alcohol or drug consumption, restraint use, license validity, and injury severity; (iii) the vehicle file lists information about make, model, registration, maneuver, collision point, and reported damage.

This study analyses crashes involving a pedestrian and a vehicle that occurred on Danish roads during the ten-year period between 2006 and 2015. Selecting pedestrian-vehicle crashes limits the noise associated with multiple vehicle crashes and their dynamics (Mohamed et al., 2013; Sasidharan and Menendez, 2015). Selecting a ten-year period guarantees a large sample size where the GIS resources correct for road and traffic variations by matching the versions of each crash year. 


\section{ACCEPTED MANUSCRIPT}

The crash database contained 6539 complete records whose severity outcomes were (i) damage only including bruises and material damages of at least 5000 DKK (about 700 USD), (ii) light injuries needing proper medical treatment, (iii) severe injuries involving incapacitation (e.g., lesions, fractures, concussions), and (iv) fatalities occurring within 30 days of the crash. Table I presents an extract of the variables according to the categories that the modelling process has found the most suited for obtaining the best model specification (the complete list of the variables is presented in table AI in the Appendix). The crash database contained also geographical coordinates for GIS resource matching as described in the following sub-section.

\section{GIS Data}

Each crash geographical location was matched with the Danish register of buildings, the Danish register of businesses, the Danish population in 1ha grid cells, the land cover dataset of the European Environment Agency, and the network and traffic data of the Danish National Transport Model (NTM) for private and public transport. Table II summarises the data extracted from these resources (the complete data are presented in table AII in the Appendix).

Road characteristics from the NTM road network corrected for incomplete records and provided up-to-date characteristics at the time of the crash by using the information for the crash year. The characteristics included category, directions, lanes, section type, intersection type and speed limits. Traffic exposure from the NTM provided road and walking traffic densities in the zone where the crash occurred.

Built environment characteristics were extracted at the street buffer level (within 500m of the crash location), and the traffic zone level (within the NTM traffic zone). At the street buffer 


\section{ACCEPTED MANUSCRIPT}

level, the characteristics grasped the effect of the immediate walking surroundings and included land use, road density, road being low speed, road being low volume, intersections, schools, leisure locations, and public transport stops or stations. At the traffic zone level, the characteristics grasped the effect of a larger area characterised by homogenous traffic and population conditions and included measures of population composition, income distribution, car ownership, job density, unemployment rate, rurality level based on a weighted average of 14 indices (for details, see Danish Ministry of Food Agriculture and Fisheries 2011), and land use diversity (Song et al., 2013).

\section{MODEL}

Spatial models have been applied sparingly in the injury severity literature (Castro et al., 2013; Mannering and Bhat, 2014) and their major drawback is the heavy computational requirement of inverting large matrices expressing the spatial correlation. With the aim of avoiding matrix inversion, this study formulates a linearised spatial logit model where the utility $U_{i n}$ of a crash $i$ leading to a pedestrian injury of severity $n$ is written as (Klier and McMillen, 2008):

$$
\begin{aligned}
& \boldsymbol{U}_{i}=\boldsymbol{\beta} \boldsymbol{X}_{i}+\boldsymbol{\rho} \boldsymbol{W} \boldsymbol{U}_{j}+\varepsilon_{i}(1) \\
& \boldsymbol{U}_{i n}=\sum_{k=1}^{K} \boldsymbol{\beta}_{k} \boldsymbol{X}_{i k}+\boldsymbol{\rho} \sum_{j=1}^{J} \boldsymbol{w}_{i j} \boldsymbol{U}_{j n}+\varepsilon_{i n}(2)
\end{aligned}
$$

where $X_{i k}$ are values for the variables $k$ expressing the characteristics of crash $i, U_{j n}$ are the utilities of each crash $j$ leading to a pedestrian injury of severity $n, w_{i j}$ are elements of the weight matrix $\boldsymbol{W}$ expressing the spatial correlation between crashes $i$ and $j, \beta_{k}$ are parameters to be estimated, $\rho$ is the spatial correlation parameter to be estimated, and $\varepsilon_{i n}$ are error terms. 


\section{ACCEPTED MANUSCRIPT}

A positive value of the parameter $\rho$ implies clustering and a negative value implies dispersion across severity outcomes of the crashes. The elements $w_{i j}$ are a function of the distance $d_{i j}$ between crashes $i$ and $j$ according to an exponent $s$ :

$$
\boldsymbol{w}_{i j}=\left\{\begin{array}{lr}
\left(\frac{1}{d_{i j}^{s}}\right) / \sum_{j=1, j \neq i}^{J}\left(\frac{1}{d_{i j}^{s}}\right) \text { for } i \neq j \\
0 \quad \text { for } \boldsymbol{i}=\boldsymbol{j}
\end{array}\right.
$$

As the estimation of spatial logit or probit models is extremely complex because of the need for inverting $(J \times J)$ matrices, the spatial logit is reformulated with a linearised generalised method of moments (Klier and McMillen, 2008):

$$
\boldsymbol{U}_{\boldsymbol{i}}=(\boldsymbol{I}-\boldsymbol{\rho} \boldsymbol{W})^{-1} \boldsymbol{X}_{\boldsymbol{i}} \boldsymbol{\beta}+(\boldsymbol{I}-\boldsymbol{\rho} \boldsymbol{W})^{-1} \varepsilon(4)
$$

where the vector $\boldsymbol{P}_{\boldsymbol{i}}$ of probabilities of pedestrian injury severity $n$ for crash $i$ is expressed as:

$$
\boldsymbol{P}_{i}=\frac{\exp \left(\boldsymbol{X}_{i}^{* *} \boldsymbol{\beta}\right)}{1+\exp \left(\boldsymbol{X}_{i}^{* *} \boldsymbol{\beta}\right)} \text { where } \boldsymbol{X}_{i}^{* *}=(\boldsymbol{I}-\boldsymbol{\rho} \boldsymbol{W})^{-1} \boldsymbol{X}_{i}^{*} \text { and } \boldsymbol{X}_{i}^{*}=\boldsymbol{X}_{i} / \boldsymbol{\sigma}_{\boldsymbol{i}}(5)
$$

where $X_{i}$ are vectors of characteristics of crash $i$ and $\sigma_{i}$ are the diagonal elements of the covariance matrices. A two-stage estimation procedure (Klier and McMillen, 2008) was implemented in the R package McSpatial: (i) estimation of a standard logit with $\rho=0$ to obtain estimates $\boldsymbol{\beta}_{0}$ and calculation of the utilities and gradient terms $G_{\beta i}=\hat{\boldsymbol{P}}_{i}\left(1-\hat{\boldsymbol{P}}_{i}\right) X_{i}$ and $G_{\rho i}=\hat{\boldsymbol{P}}_{i}\left(1-\hat{\boldsymbol{P}}_{i}\right) \boldsymbol{W} X_{i} \hat{\boldsymbol{\beta}}$ at estimates; (ii) regression of the vectors $\boldsymbol{G}_{\boldsymbol{\beta}}$ and $\boldsymbol{G}_{\boldsymbol{\rho}}$ on the instruments $Z$ corresponding to the geographical coordinates of the crashes, calculation of the predicted values $\hat{\boldsymbol{G}}_{\boldsymbol{\beta}}$ and $\hat{\boldsymbol{G}}_{\boldsymbol{\rho}}$, regression of $\boldsymbol{U}^{0}+\hat{\boldsymbol{G}}_{\boldsymbol{\beta}} \hat{\boldsymbol{\beta}}_{0}$ on $\hat{\boldsymbol{G}}_{\boldsymbol{\beta}}$ and $\hat{\boldsymbol{G}}_{\boldsymbol{\rho}}$, and retrieval of the parameters $\beta_{k}$ and $\rho$. 


\section{ACCEPTED MANUSCRIPT}

\section{MODEL RESULTS}

The initial estimation of aspatial models revealed that the binary model considering two different injury severity levels, namely damage only / light injury versus severe injury / fatality, was performing better than the multinomial model considering the four different levels: in the latter model, the estimates for the two lower severity levels and the ones for the two higher severity levels were not statistically different. Figure I presents the spatial distribution of the pedestrian injury severity levels for the analysed crashes alongside a classification of the areas and the highlight of the five major cities in Denmark.

The linearised spatial logit model was estimated with the aim of searching the best model specification for the two aforementioned injury severity levels. The iterative process progressively considered additional variables in the model and the best specification retained continuous and categorical variables that were significant at least at the 0.10 level (for a discussion about retaining variables on the basis of their significance levels, see Kockelman, 2002) and showed a low variance inflation factor. The best model specification was obtained for s equal to 3 (similar to Klier \& McMillen, 2008). A likelihood ratio test showed that the linearised spatial logit is a significant improvement over a binary logit with $\rho$ equal to 0 (LRT $=$ $16.74, \mathrm{p}=0.000)$, and the Hansen's (1982) test $(\mathrm{J}$-test $=0.142, \mathrm{p}=0.001)$ proved the validity of the estimator and the instruments. Tables III and IV present and extract of the estimates and the marginal effects for the binary logit and the spatial logit models with the best model

specification: (i) the model estimates represent the estimated parameters $\beta_{k}$ and $\rho$ where each $\beta_{k}$ represents the logarithm of the odds-ratio for the considered level of the factor as compared to the reference level of the factor; (ii) the marginal effects represent the relative increase (or 


\section{ACCEPTED MANUSCRIPT}

reduction) of the probability of the pedestrian experiencing severe or fatal injury for the considered level of the factor, as compared to the reference level of this factor.. The most notable difference between the two models is that the marginal effects of the logit model are biased towards an under-estimation of the effects of the factors on the injury severity levels. The comments on the results pertain the spatial logit model as the best model. Please refer to estimates and marginal effects for all the variables in tables AIII and AIV in the Appendix

\section{Characteristics of Pedestrians, Vehicles and Crashes}

From the pedestrian perspective, with the exclusion of children and young adolescents, younger and older pedestrians are associated respectively with a lower and higher probability of sustaining severe or fatal injuries, in line with existing findings of higher severity with increasing age (Eluru et al., 2008; Clifton et al., 2009; O’Hern et al., 2015; Sasidharan and Menendez, 2015). Pedestrian intoxication is also positively related to a higher probability of suffering severe or fatal injuries, in line with previous studies (Kim et al., 2008; Clifton et al., 2009). This model adds the perspective that foreigners are associated with less severe outcomes when involved in pedestrian crashes.

From the other road user perspective, this model confirms previous findings about heavy vehicles being related to higher injury severity (Abay, 2013; Mohamed et at., 2013; Sasidharan and Menendez, 2015; Verzosa and Miles, 2016), but adds the original perspectives of vans and pickup trucks not having an effect different from cars, and two-wheelers causing less severe consequences than cars. Also, the model adds some perspective: male drivers are related to higher severity for the pedestrians, while older drivers are associated with lower severity for the 


\section{ACCEPTED MANUSCRIPT}

pedestrians. Notably, unlike previous studies (Kim et al., 2008; Eluru et al., 2008; Abay, 2013), the level of intoxication of drivers is not related to pedestrian injury severity.

From the pedestrian behaviour perspective, walking along or at the side of the road is associated with lower severity with respect to crossing, in disagreement with existing studies (Kim et al., 2008; Rothman et al., 2012; Abay, 2013; Sasidharan and Menendez, 2015) that, however, did not correct for spatial correlation and omitted built environment variables. From the driver behaviour perspective, the model confirms existing findings about the relation between turning manouvers and lower severity (Eluru et al., 2008; Abay, 2013; Mohamed et al., 2013), but also adds the perspective of reversing maneuvers being related to lower severity.

From the environment perspective, lower severity is associated with autumn and winter seasons and poor visibility, while higher severity is related to wet or slippery surface conditions as well as afternoon peak, evening and night conditions, in agreement with existing research (Mohamed et al., 2013; Verzosa and Miles, 2016). This model adds that artificial illumination mitigates the negative effect of darkness and afternoon peak (and not peak hours in general) is associated with more severe crash outcomes for pedestrians.

\section{Characteristics of the Built Environment}

The model confirms that the higher the speed limits, the higher the pedestrian injury severity (Eluru et al., 2008; Abay, 2013), and adds that curve road sections are related to higher severity when compared to straight road sections or intersections.

At the street buffer level, the land use in proximity of the crash is significantly associated with the injury severity. When compared to open areas, residential areas are related to lower 


\section{ACCEPTED MANUSCRIPT}

injury severity (in particular low-rise buildings) and so are industrial and shopping areas. These findings contradict the few studies that analysed the influence of the built environment (MirandaMoreno et al., 2011; Mohamed et al., 2013) albeit without accounting for spatial correlation across crashes. This model adds the perspective of a higher share of low speed roads in the crash surroundings being also related to lower probability of severe and fatal injuries.

At the traffic zone level, differences across regions are observed as Mid- and South-Jutland are related to higher injury severity, even after controlling for spatial correlation and built environment. Areas classified as intermediate are related to lower injury severity with respect to urban areas, even after controlling for the land use in proximity of the crash. This model provides additional perspectives by finding an association of higher injury severity with the distance between hospitals and crash locations, confirming what observed in Denmark for low volume rural roads (Prato et al., 2014), as well as a relation between lower injury severity and walking traffic density, suggesting that the "safety in numbers" paradigm (Jacobsen, 2003) applies also to pedestrians and not only to cyclists (Kaplan and Prato, 2015).

\section{CONCLUSIONS}

This study presents a linearised spatial logit model of the injury severity suffered by pedestrians in crashes with another road user in Denmark. The contribution of this study lies in the extensive coverage of the aggravating and mitigating factors of pedestrian injury severity, including the often omitted characteristics of the built environment and traffic exposure, as well as the consideration of spatial correlation.

Limitations apply to this study, in particular as police reports are often incomplete and crashes are often under-reported. Enriching the police data with GIS resources mitigates the 


\section{ACCEPTED MANUSCRIPT}

former, while considering crashes between pedestrians and another road user limits the latter (see, e.g., Mohamed et al., 2013; Sasidharan and Menendez, 2015; Janstrup et al. 2016). Also, a binary model was estimated and the effects of the linearization of the spatial logit in a multinomial setting was not explored fully. Albeit limitations exist, the findings from this study provide food for thought when thinking about mitigating pedestrian injury severity.

Firstly, the findings confirm that older pedestrians and intoxicated pedestrians are the most vulnerable road users. Albeit investments are made substantially in campaigns about the risks of drinking and driving, it seems that they should be extended to vulnerable road users as similar findings were found also for cyclists (Kaplan et al., 2014). Further research should investigate whether walking or cycling under the influence is socially accepted and should promote shared responsibility as a concept that makes roads safer.

Secondly, the findings suggest the need for thinking about traffic calming and other measures for mitigating the outcomes of crashes for pedestrians. Traffic calming needs to make simpler for pedestrians to cross, as it is the event associated with higher injury severity, and for other road users to approach, as going straight is related to higher injury severity. It appears that attention should be posed towards illumination, especially in the darkest hours, road surface maintenance, especially when there are precipitations, and speed limits, especially in rural areas. The findings point to these elements being relevant to higher injury severity, and thus further research should test solutions via before-after studies.

Thirdly, the findings emphasise the role of the built environment in the proximity of the crash. Results indicate that shopping areas, residential areas, low speed roads, and walking traffic density are positively related to a reduction in pedestrian injury severity. Often, these areas have 


\section{ACCEPTED MANUSCRIPT}

in common a larger pedestrian mass that is more likely to make other road users more aware and attentive, and the same does not seem to apply to intermediate and rural areas. Further research

should investigate what triggers awareness and attention in particular in drivers, and how hazards could be recognised more easily in areas with lower pedestrian density. 


\section{ACCEPTED MANUSCRIPT}

\section{REFERENCES}

Abay K. Examining pedestrian-injury severity using alternative disaggregate models. Res Transp Econ 2013;43: 123-136.

Castro M, Paleti R, Bhat CR. A spatial generalized ordered response model to examine highway crash injury severity. Accid Anal Prev 2013;52:188-203.

Clifton KJ, Burnier CV, Akar G. Severity of injury resulting from pedestrian-vehicle crashes: What can we learn from examining the built environment? Transport Res D-TrE $2009 ; 14: 425-436$.

Danish Ministry of Food, Agriculture and Fisheries. The Danish Rural Development Programme 2007-2013. http://agrifish.dk/rural_development.aspx?ID=46534, Copenhagen, Denmark, 2011.

Eluru N, Bhat CR, Hensher DA. A mixed generalized ordered response model for examining pedestrian and bicyclist injury severity level in traffic crashes. Accid Anal Prev 2008;40:1033-1054.

Elvik R. The non-linearity of risk and the promotion of environmentally sustainable transport. Accid Anal Prev 2009;41:849-855.

Hansen LP. Large sample properties of Generalized Method of Moments estimators. Econometrica 1982;50: 1029-1054.

Jacobsen P. Safety in numbers: more walkers and bicyclists, safer walking and bicycling. Injury Prev 2003;9:205-209. 


\section{ACCEPTED MANUSCRIPT}

Janstrup KH, Kaplan S, Hels T, Lauritsen J, Prato CG. Understanding traffic crash underreporting: Linking police and medical records to individual and crash characteristics. Traffic Inj Prev 2016;17:580-584.

Kaplan S, Prato CG. A spatial analysis of land use and network effects on frequency and severity of cyclist-motorist crashes in the Copenhagen region. Traffic Inj Prev 2015;16:724-731.

Kaplan S, Vavatsoulas K, Prato CG. Aggravating and mitigating factors associated with cyclist injury severity in Denmark. J Safety Res 2014;50:75-82.

Kim J, Ulfarsson G, Shankar V, Kim S. Age and pedestrian injury severity in motor-vehicle crashes: a heteroskedastic logit analysis. Accid Anal Prev 2008;40:1695-1702.

Klier T, McMillen DP. Clustering of auto supplier plants in the United States. J Bus Econ Stat 2008;26:460-471.

Kockelman, KM. Driver injury severity: an application of ordered probit models. Accid Anal Prev 2002;34:313-321.

Lee C, Abdel-Aty M. Comprehensive analysis of vehicle-pedestrian crashes at intersections in Florida. Accid Anal Prev 2005;37:775-786.

Mannering FL, Bhat CR. Analytic methods in accident research: Methodological frontier and future directions. Anal Method Accid Res 2014;1:1-22.

Miranda-Moreno LF, Morency P, El-Geneidy AM. The link between built environment, pedestrian activity and pedestrian-vehicle collision occurrence at signalized intersections. Accid Anal Prev 2011;43:1624-1634. 


\section{ACCEPTED MANUSCRIPT}

Mohamed GM, Saunier N, Miranda-Moreno LF, Ukkusuri SV. A clustering regression approach: A comprehensive injury severity analysis of pedestrian-vehicle crashes in New York, US and Montreal, Canada. Safety Sci 2013;54:27-37.

O’Hern S, Oxley J, Logan D. Older adults at increased risk as pedestrians in Victoria, Australia: An examination of crash characteristics and injury outcomes. Traffic Inj Prev 2015;16:S161S167.

Prato CG, Rasmussen TK, Kaplan S. Risk factors associated with crash severity on low-volume rural roads in Denmark. J Transp Safety Security 2014;6:1-20.

Pucher J, Buehler R. Making Cycling Irresistible: Lessons from The Netherlands, Denmark and Germany. Transport Rev 2008;28:495-528.

Rothman L, Howard AW, Camden A, Macarthur C. Pedestrian crossing location influences injury severity in urban areas. Injury Prev 2012;18:365-370.

Roudsari B, Mock CN, Kaufman R. An evaluation of the association between vehicle type and the source and severity of pedestrian injuries. Traffic Inj Prev 2005;6:185-192.

Sasidharan L, Wu KF, Menendez M. Exploring the application of latent class cluster analysis for investigating pedestrian crash injury severities in Switzerland. Accid Anal Prev 2015;85:219228.

Savolainen PT, Mannering FL, Lord D, Quddus MA. The statistical analysis of highway crashinjury severities: a review and assessment of methodological alternatives. Accid Anal Prev 2011;43:1666-1676.

Song Y, Merlin L, Rodriguez D. Comparing measures of urban land use mix. Comput Environ Urban Syst 2013;42:1-13. 


\section{ACCEPTED MANUSCRIPT}

Strandroth J, Rizzi M, Sternlund S, Lie A, Tingvall C. The correlation between pedestrian injury severity in real-life crashes and Euro NCAP pedestrian test results. Traffic Inj Prev 2011;12:604-613.

Verzosa N, Miles R. Severity of road crashes involving pedestrians in Metro Manila, Philippines. Accid Anal Prev 2016;94:216-226.

Zahabi S, Strauss J, Manaugh K, Miranda-Moreno LF. Estimating potential effect of speed limits, built environment, and other factors on severity of pedestrian and cyclist injuries in crashes. Transport Res Rec 2011;2247:81-90. 


\section{ACCEPTED MANUSCRIPT}

\section{APPENDIX}

$<\mathrm{AQ}>$ Please Provide Content for Appendix table I to IV. $</ \mathrm{AQ}>$ 


\section{ACCEPTED MANUSCRIPT}

Table I Crash characteristics

\begin{tabular}{|c|c|c|c|c|}
\hline Variable & Category & $\%$ & Category & $\%$ \\
\hline \multicolumn{5}{|c|}{ Characteristics of the pedestrian } \\
\hline \multirow[t]{2}{*}{ Injury severity } & No injury & 45.4 & Severe injury & 32.1 \\
\hline & Light injury & 17.4 & Fatality & 5.1 \\
\hline Gender & Male & 46.5 & Female & 53.5 \\
\hline \multirow[t]{5}{*}{ Age } & $<=9$ years old & 7.5 & $40-49$ years old & 11.1 \\
\hline & $10-14$ years old & 7.9 & $50-59$ years old & 10.3 \\
\hline & $15-19$ years old & 10.8 & $60-69$ years old & 9.5 \\
\hline & 20-29 years old & 15.2 & $>=70$ years old & 17.4 \\
\hline & 30-39 years old & 10.4 & & \\
\hline Intoxicated & No & 89.1 & Yes & 10.9 \\
\hline \multirow[t]{4}{*}{ Behaviour } & Crossing from the right & 36.5 & Walking on the pavement & 5.1 \\
\hline & Crossing from the left & 27.4 & Standing on the road & 10.6 \\
\hline & Hidden & 8.8 & Hit by reversing vehicle & 6.0 \\
\hline & Walking along the road & 5.6 & & \\
\hline Nationality & Danish & 86.9 & Foreigner & 13.1 \\
\hline
\end{tabular}




\section{ACCEPTED MANUSCRIPT}

Table II GIS data characteristics

\begin{tabular}{|c|c|c|c|c|}
\hline Variable & Category & Value & Category & Value \\
\hline \multicolumn{5}{|c|}{ Built environment at the street buffer level (within $500 \mathrm{~m}$ of the crash location) } \\
\hline \multirow[t]{4}{*}{ Roadside land use } & Shopping street $(\%)$ & 17.4 & Low residential area $(\%)$ & 19.2 \\
\hline & & & Buildings with no access & \\
\hline & Industrial area $(\%)$ & 6.4 & $(\%)$ & 6.3 \\
\hline & High residential area $(\%)$ & 35.6 & Spare buildings $(\%)$ & 15.1 \\
\hline \multicolumn{5}{|c|}{ Built environment at the traffic zone level (within the NTM zone) } \\
\hline $\begin{array}{l}\text { Unemployment } \\
\text { rate }\end{array}$ & mean $(\%)$ & 7.2 & st. dev. $(\%)$ & 3.0 \\
\hline \multirow[t]{3}{*}{ Region } & Copenhagen $(\%)$ & 37.6 & North Jutland (\%) & 8.0 \\
\hline & Zealand (\%) & 12.1 & Mid-Jutland (\%) & 20.1 \\
\hline & Fyn $(\%)$ & 9.4 & South Jutland (\%) & 12.8 \\
\hline Rural index of the & Urban $(\%)$ & 56.5 & Rural (\%) & 22.4 \\
\hline municipality & Intermediate $(\%)$ & 14.9 & Peripheral (\%) & 6.2 \\
\hline $\begin{array}{l}\text { Distance to } \\
\text { hospital }\end{array}$ & mean $(\mathrm{km})$ & 5.6 & st. dev. (km) & 6.9 \\
\hline
\end{tabular}

\section{Exposure measures (per NTM zone)}

Road traffic

mean $\left(1000 \mathrm{veh} / \mathrm{day} / \mathrm{km}^{2}\right)$

st. dev. $(1000$

density

26.3

$\mathrm{veh} / \mathrm{day} / \mathrm{km}^{2}$ ) 


\section{ACCEPTED MANUSCRIPT}

\begin{tabular}{llll} 
Walking traffic & mean $(1000$ walk- & st. dev. $(1000$ walk- & 12.8 \\
density & 5.5 & & $\left.\mathrm{~km} / \mathrm{day} / \mathrm{km}^{2}\right)$ \\
& $\mathrm{km} /$ day $\left./ \mathrm{km}^{2}\right)$ & & \\
\hline
\end{tabular}




\section{ACCEPTED MANUSCRIPT}

Table III Model estimates

\begin{tabular}{|c|c|c|c|c|c|}
\hline Variable & Category & est. & Sig & est. & Sig \\
\hline \multicolumn{6}{|c|}{ Built environment at the traffic zone level (within the NTM zone) } \\
\hline Unemployment rate & $\log (\%)$ & 0.175 & ** & 0.181 & ** \\
\hline \multirow[t]{5}{*}{ Region } & Copenhagen & - & & - & \\
\hline & Zealand & -0.208 & ** & -0.220 & ** \\
\hline & Fyn / South Jutland & -0.155 & * & -0.158 & * \\
\hline & Mid-Jutland & 0.083 & & 0.102 & * \\
\hline & North Jutland & 0.168 & * & 0.204 & * \\
\hline Rural index of the & Urban & - & & - & \\
\hline \multirow[t]{2}{*}{ municipality } & Intermediate & -0.226 & ** & -0.241 & ** \\
\hline & Rural / Peripheral & -0.037 & * & -0.038 & * \\
\hline Distance to hospital & $\mathrm{km}$ & 0.007 & & 0.007 & \\
\hline
\end{tabular}

\section{Exposure measures (within the NTM zone)}

Walking traffic

density

$$
\log \left(100 \text { walk-km/day } / \mathrm{km}^{2}\right)
$$

$-0.044$

$-0.045$

\begin{tabular}{lrc}
\hline Spatial parameter $\rho$ & - & $0.296^{* *}$ \\
\hline Number of estimated parameters & 48 & 49 \\
Initial log-likelihood & -4532.49 & -4532.49 \\
Final log-likelihood & -3887.87 & -3879.50 \\
Adjusted rho-square & 0.132 & 0.133 \\
\hline
\end{tabular}




\section{ACCEPTED MANUSCRIPT}

Table IV Marginal effects

\begin{tabular}{llcc}
\hline Variable & Category & logit & spatial logit \\
\hline \multicolumn{2}{c}{ Built environment at the traffic zone level (within the NTM zone) } \\
Unemployment rate & $\log (\%)$ & $10.2 \%$ & $11.2 \%$ \\
\hline Region & Copenhagen & - & - \\
& Zealand & $-10.4 \%$ & $-12.4 \%$ \\
& Fyn / South Jutland & $-7.7 \%$ \\
& Mid-Jutland & $-5.9 \%$ & $13.1 \%$ \\
& north Jutland & $9.6 \%$ & $22.0 \%$ \\
\hline Rural index of the & Urban & $17.1 \%$ & - \\
municipality & Intermediate & $-14.6 \%$ & $-17.6 \%$ \\
& Rural / Peripheral & $-2.1 \%$ & $-2.4 \%$ \\
\hline Distance to hospital & km & $2.5 \%$ & $2.6 \%$ \\
\hline & Exposure measures (within the NTM zone) & \\
Walking traffic & & $-2.7 \%$ & $-2.9 \%$ \\
density & log (100 walk-km/day/km $\left.{ }^{2}\right)$ & \\
\hline & & & \\
\hline
\end{tabular}




\section{ACCEPTED MANUSCRIPT}

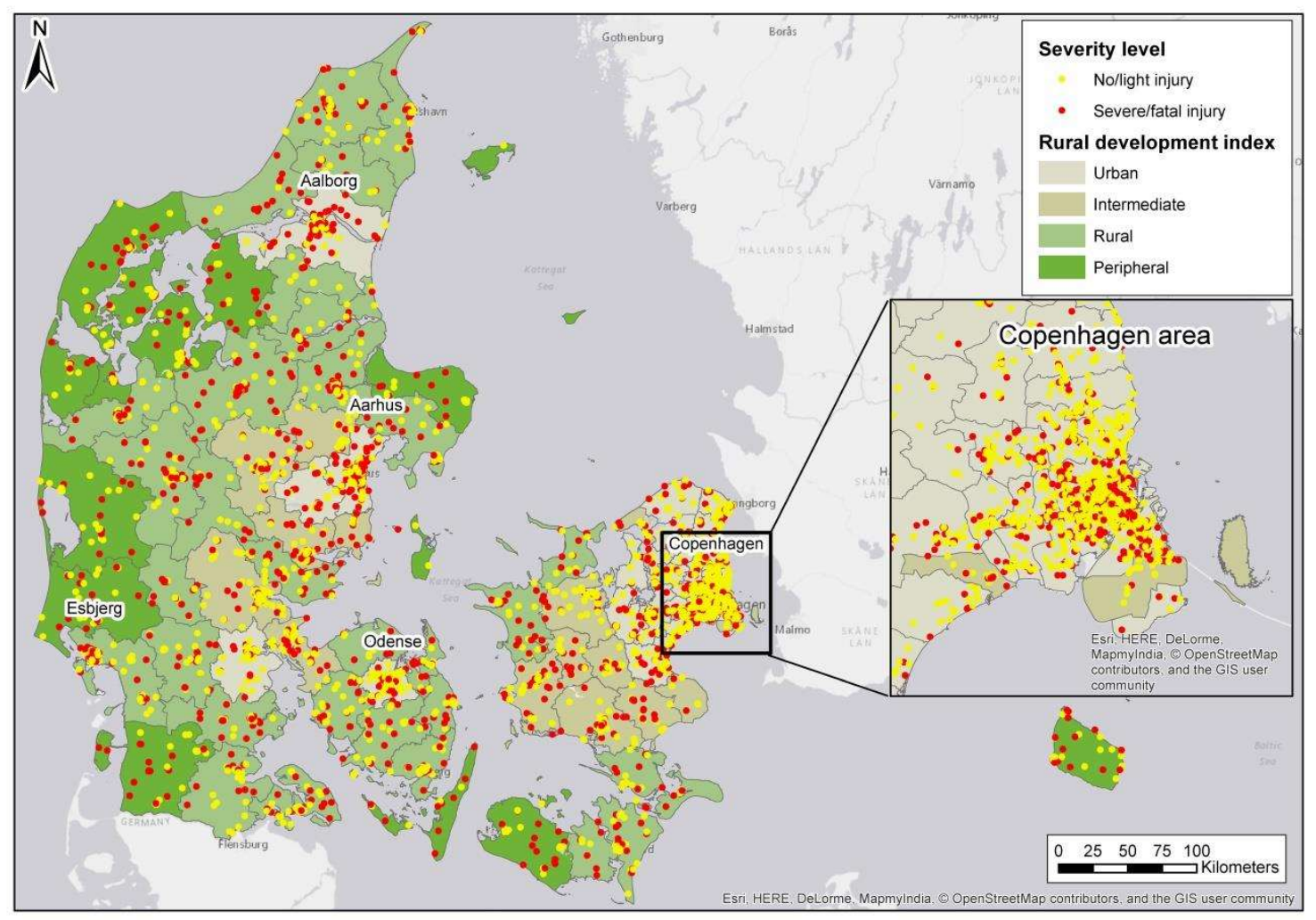

Figure I Spatial distribution of pedestrian crashes in Denmark 